\title{
Supplementation with carnitine for weight loss: a biochemical approach
}

\author{
José Henry Osorio, PhD*
}

\section{SUMMARY}

Carnitine is a molecule involved in transporting activated fatty acids among different cellular compartments, which is most likely present in all animal species, and in numerous microorganisms and plants. Recently the trend in the field of weight control is to include carnitine in the diet as an agent responsible for weight loss. In the present review, some findings are discussed from a biochemical point of view to illustrate if the use of carnitine for weight loss can be considered fiction or reality.

Keywords: Carnitine; Lipid metabolism; Weight loss.

Colomb Med. 2011; 42: 529-35

\section{Suplementación con carnitina para perder peso: Una aproximación bioquímica}

\section{RESUMEN}

La carnitina es una molécula involucrada en el transporte de ácidos grasos activados, entre diferentes compartimentos celulares, la cual posiblemente está presente en todas las especies animales, así como en numerosos microorganismos y plantas. Recientemente, la tendencia en el campo del control de peso incluye la introducción de carnitina en la dieta, como un agente responsable de la pérdida de peso. En el presente artículo de revisión, se discuten algunos hallazgos, desde un punto de vista bioquímico, para ilustrar si el uso de carnitina para la pérdida de peso puede considerarse fícción o realidad.

Palabras clave: Carnitina; Metabolismo lipídico; Pérdida de peso.

Colomb Med. 2011; 42: 529-35

Recently, an increasing number of people believe that carnitine is an important substance, which can be supplemented in diets for weight loss in humans, as well as in pets; hence, it is common to find in the marketplace a variety of products supplemented with carnitine or even pure carnitine to consume for weight loss purposes; however, many doubts remain in the field of nutrition related to the veracity of this postulate, making it necessary to delve into the metabolic ways in which this molecule is implicated.

Carnitine was discovered in muscle extracts and reported separately in 1905. Its molecular structure (3hydroxy-4-N-trimethyl-aminobutyric acid) was established in 1927 and the name carnitine originates from the Latin word for flesh or meat, carno.
In 1952, Carter et al. ${ }^{1}$, found that carnitine was essential for the growth of the yellow mealworm, Tenebrio molitor, and it was also discovered that carnitine was present in a wide range of biological materials and that carnitine could be reversibly acetylated with acetyl-coenzyme A (CoA).

Carnitine is present in tissues and body fluids as free and as esterified short-chain, medium-chain, and longchain acylcarnitines. Total carnitine consists of the sum of free carnitine and all acylcarnitines. Animal tissues contain relatively large amounts of carnitine, varying between 0.2 and $6 \mu \mathrm{mol} / \mathrm{g}$, with the highest concentrations in heart and skeletal muscle ${ }^{2}$.

The role of carnitine in fatty acid oxidation was discovered in 1955, while working with liver homo-

* Research laboratory in clinical biochemistry and molecular pathology, Department of Basic Sciences for Health, Universidad de Caldas, Manizales, Colombia. e-mail: jose.osorio_o@ucaldas.edu.co

Received for publication December 9, 2010 Accepted for publication April 17, 2011 
genates, and the configuration of the physiological enantiomer was determined as L(-) or R(-)-3-hydroxy4-N,N,N-trimethylaminobutyrate by Kaneko and Yoshida in $1962^{3}$. The main function of carnitine is to shuttle activated long-chain fatty acids [fatty acylcoenzyme A (CoA)] from the cytosol into the mitochondrial matrix for $\beta$-oxidation, and to remove short-chain, medium-chain, and long-chain fatty acids that accumulate as a result of normal and abnormal metabolism ${ }^{4}$. Thereby, carnitine helps to maintain adequate cellular levels of free $\mathrm{CoA}$; furthermore, products from the peroxisomal $\beta$-oxidation system, including acetyl-CoA, are transported as carnitineesters from peroxisomes to mitochondria for complete degradation to $\mathrm{CO}_{2}$ and $\mathrm{H}_{2} \mathrm{O}$. Carnitine can also modulate the toxic effects of poorly metabolised acyl-groups of either xenobiotic origin (e.g. pivalic acid and valproate) or those arising from various inborn errors of metabolism, and it can also interact with membranes to change their physiochemical properties ${ }^{5}$. This means that carnitine modulates the acyl-CoA/free $\mathrm{CoA}$ ratio via the formation of acyl-carnitines. If acyl-CoAs are produced faster than they are utilised, intramitochondrial free CoA is regenerated as carnitine, which binds the acyl-groups, thus, restoring the normal intra-mitochondrial acyl-CoA/free CoA ratio ${ }^{6}$.

The present review analyses the use of carnitine for fat burning, remarking the main biochemical aspects related to the subject. First of all, the way fat is physiologically burnt by the normal organism is studied, and two more sections are included, one section shows the sources of carnitine for humans and the destiny of carnitine under different conditions, and the latter section analyses the supplementation of carnitine for weight loss.

\section{DEGRADATION OF FATTY ACIDS}

Fatty acids (FA) are stored in adipose tissue during periods of good feeding, and they are the major source of energy for the heart and the skeletal muscle, and one of the most important processes for producing fuel during endurance exercise and starvation. FA provide as much as $80 \%$ of the energy for heart and liver function, and the oxidation of long-chain FA also provides the energy for non-shivering thermogenesis by brown adipose tissue ${ }^{7}$. The study of FA biological degradation was done in 1904 when Knoop performed experiments with dogs, which led him to formulate the theory of $\beta$-oxidation. This pathway is responsible for the degradation of FA to produce acetyl-CoA, and the mitochondrial location of this pathway agreed with the observed coupling of FA oxidation to the citric acid cycle and to oxidative phosphorylation ${ }^{8}$.

Most tissues are able to degrade FA to $\mathrm{CO}_{2}$ and $\mathrm{H}_{2} \mathrm{O}$, but the liver has the unique capacity to synthesise ketone bodies, acetoacetate and 3-hydroxybutyrate from acetyl-CoA, supplying an important fuel to other organs, mainly the brain 9 .

In addition, peroxisomes and glyoxysomes, collectively referred to as micro bodies, are sub-cellular organelles that do not have an energy-coupled electron transport system, but instead contain flavine oxidases, which catalyse the substrate-dependent reduction of oxygen to $\mathrm{H}_{2} \mathrm{O}_{2}$. Within a few years of the identification of peroxisomal $\beta$-oxidation in animals, the pathway was elucidated and the liver enzymes had been purified and characterised ${ }^{10}$. FA are activated by acyl-CoA synthetase on the peroxisomal membrane and the entry into the organelle is independent of carnitine. Substrates that are preferably, or exclusively, oxidised in peroxisomes include very long-chain FA, polyunsaturated FA, dicarboxylic acids, prostaglandins, eicosanoids, pristanic acid, bile acid intermediates, and side chains of xenobiotics, which are not metabolised or poorly metabolised by mitochondria, and the side chain of cholesterol $^{11}$.

The mitochondrial $\beta$-oxidation pathway. Physiologically available FA are mostly $\mathrm{C} 16$ and $\mathrm{C} 18$ species and include saturated and both mono- and di-unsaturated species. The tissue uptake of FA and their transfer from the cell membrane to the place of $\beta$-oxidation remain poorly understood. FA transporters (FATP) and cytosolic FA-binding proteins (FABP) are probably involved in these processes ${ }^{12}$.

For mitochondrial $\beta$-oxidation, long-chain FA are activated to their CoA esters by Acyl-CoA synthase in the cytosol and on the mitochondrial outer membrane; the mitochondrial inner membrane is impermeable to acyl-CoA esters. Carnitine is supplied into the cell by a plasma membrane carnitine transporter commonly referred to as OCTN2, located in the cellular membrane, and three enzymes: carnitine palmitoyltransferase I (CPT I) in the outer mitochondrial membrane; carnitine/ 
acylcarnitine translocase (CACT) within the inner mitochondrial membrane, and carnitine palmitoyltransferase (CPT II) in the inner mitochondrial membrane (carnitine O-palmitoyltransferase EC 2.3.1.21) are responsible for the reversible reaction: acyl$\mathrm{CoA}+$ carnitine $=$ acylcarnitine $+\mathrm{CoA}-\mathrm{SH}$. The regulation of mitochondrial FA oxidation mainly involves CPT I. In the liver, CPT I controls the FA flux through the esterification and oxidative pathways, given its sensitivity to malonyl-CoA, a potent CPT I inhibitor that is the first committed intermediate in the pathway of FA biosynthesis ${ }^{13}$. During fasting, the malonyl-CoA level decreases, and CPT I becomes uninhibited, then long-chain fatty acid (LCFA) oxidation and subsequent ketogenesis become enhanced. In the post-absorptive state, the concentration of malonyl-CoA rises, CPT I is thereafter inhibited, and newly formed LCFA are directed towards esterification. Fatty Acids of less than 12 carbons, such as those provided by dietary supplements of medium-chain triglycerides, can enter the mitochondria and are activated within the mitochondrial matrix independent of the carnitine transport system ${ }^{14}$.

The $\boldsymbol{\beta}$-oxidation spiral. Once inside the mitochondria, the fatty acyl-CoA is degraded through four separate reactions. The enzyme responsible for the first step is an acyl-CoA dehydrogenase, which transfers the electrons to an electron-transfer flavoprotein (ETF) and Coenzyme $\mathrm{Q}$ of the respiratory chain by using a second flavoprotein ETF: CoQ oxidorreductase, also named ETF dehydrogenase.

The second step is carried out by an enoyl-CoA hydratase, and the enzyme involved in the third step is an L 3-hydroxyacyl-CoA dehydrogenase using NAD as cofactor for the reaction, which is reduced to NADH transferring electrons to complex 1 of the respiratory chain. After the fourth step in which a 3-ketoacyl-CoA thiolase is involved, cycling continues until the final thiolytic cleavage with the production of two acetylCoA molecules. The acetyl-CoA produced is used directly in muscle as an energy substrate through the citric acid cycle, whilst in the liver it is degraded for the production of ketone bodies as an energy source in tissues such as brain ${ }^{15}$.

The distribution of the enzymes into the mitochondria is divided in membrane-bound enzymes and mitochondrial matrix enzymes.
The enzymes for theb-oxidation of long- to mediumchain fatty acids (C-18 to $\mathrm{C}-12$ ) are located close to the inner mitochondrial membrane, they are: very-longchain acyl-CoA dehydrogenase, long-chain enoyl-CoA hydratase, long-chain L 3-hydroxyacyl-CoA dehydrogenase and long-chain 3-ketoacyl-CoA thiolase. The activity for the last three enzymes is found within a multiple complex known as the mitochondrial trifunctional protein (TFP) ${ }^{16}$.

The enzymes located within the mitochondrial matrix are responsible for $\beta$-oxidation of the medium- to shortchain acyl-CoA intermediates, including long-chain, medium-chain, and short-chain acyl-CoA dehydrogenases; a short-chain hydratase, also named crotonase; a medium-/short-chain 3-hydroxyacyl-CoA-dehydrogenase; and both medium-chain and short-chain 3-keto acyl CoA thiolases ${ }^{17}$.

Unsaturated FA oxidation requires auxiliary enzymes. $\mathrm{D}^{3}, \mathrm{D}^{2}$-enoyl-CoA isomerase and 2,4-dienoylCoA reductase are the auxiliary enzymes for $\alpha$-oxidation of FA with double bond at an odd- and even-numbered position, respectively (linoleate isomerase E.C.5.2.1.5; cis-2-enoyl CoA reductase E.C.1.3.1.37; trans-2-enoyl CoA reductase E.C.1.3.1.38). The above-mentioned isomerase catalyses the isomerisation of both 3-cis and 3-trans-enoyl-CoAs to 2-trans-enoyl-CoAs. Enoyl-CoA isomerases for short-, medium- and long-chain substrates have been identified, and an isoform of mitochondrial 2,4-dienoyl-CoA reductase has been reported ${ }^{18}$.

Sources of carnitine for humans. Carnitine synthesis in mammals is carried out from the turnover of proteins containing lysine residues, which are previously posttranslationally trimethylated with the release of trimethyllysine. The rate-limiting step in the pathway is the hepatic enzyme, $\gamma$-butyrobetaine hydroxylase; however, the rate of carnitine biosynthesis is mainly determined by the rate of protein turnover that supplies trimethyllysine ${ }^{19}$.

In humans, $98 \%$ of the carnitine resides in the skeletal and cardiac muscle with $1.6 \%$ in the liver and kidney, and $0.4 \%$ in the extra cellular fluid. Humans obtain most of their carnitine (some $50 \%$ to $75 \%$ of daily requirements) through dietary intake (meat, poultry, fish, and dairy products); with L-carnitine being primarily synthesised in the liver and also in the kidney and brain from protein-derived 6-N-trimethyllysine via 3-hydroxy-6-N-trimethyllysine, 4-N- 
trimethylaminobutyraldehyde and 4-N trimethylaminobutyrate (4-N-butyrobetaine). Other cells depend on carnitine import via active uptake from the blood. This transport system is also involved in the renal tubular reabsorption and intestinal absorption of carnitine ${ }^{20}$.

There is no degradation pathway for carnitine in mammals, although there is minor degradation of dietary carnitine by intestinal bacteria (less than $1 \%$ to $2 \%$ in total), and carnitine is eliminated via urine as free carnitine and acylcarnitines with renal fractional reabsorption of up to $90 \%$. Carnitine uptake into tissues and cells occurs by a saturable sodium-dependent transport mechanism ${ }^{21}$, and a failure of its transport mechanism leads to systemic or primary carnitine deficiency associated with low levels of free and total carnitine in tissues and plasma. Also, during periods of metabolic decompensation in which acyl-CoA esters accumulate, the concentration of acylcarnitines greatly increases and exceeds the capacity for L-carnitine biosynthesis (and of dietary sources), leading to a secondary carnitine deficiency ${ }^{22}$.

Supplementation with carnitine. It has been scientifically recognized that carnitine can be supplemented to improve some clinical conditions like anorexia ${ }^{23}$; cardiovascular disease, angina and ischemia ${ }^{24}$; cardiogenic shock ${ }^{25}$; cardiomyopathy ${ }^{26,27}$; myocardial infarction $^{28}$; hyperlipidemia ${ }^{29}$; insulin resistance ${ }^{30}$; painful diabetic neuropathy ${ }^{31}$; chronic fatigue syndrome ${ }^{32}$; fatty liver ${ }^{33}$; hepatitis and hepatic encephalopathy ${ }^{34}$; immunity problems ${ }^{35}$; hyperthyroidism $^{36}$; male infertility ${ }^{37}$; renal failure/dialysis ${ }^{38,39}$; respiratory distress in premature infants ${ }^{40}$, and inherited inborn errors of fatty-acid oxidation ${ }^{41}$.

The levels of endogenous L- carnitine, under normal conditions, can be influenced by long-term changes in dietary habits and nutritional status ${ }^{42}$, some authors pointed out that inasmuch as carnitine is not considered a true 'vitamin' and, under normal conditions, healthy humans can synthesise sufficient amounts of it ${ }^{43}$, individuals who consumed diets low in L-carnitine (vegetarian diets) had lower plasma L-carnitine levels than subjects consuming a mixed diet, with children being affected to a greater extent than adults. Despite large variations in dietary intake, the mean plasma levels of the compound vary by only about $20 \%$. This is understandable as renal excretion of L-carnitine is substantially less in those individuals with low dietary intake $^{42}$. Therefore, carnitine biosynthesis and renal conservation mechanisms are generally implicated and adequate to prevent overt carnitine deficiency in individuals who self-select diets that are low in carnitine ${ }^{42}$.

Dietary L-carnitine intake can vary significantly between strict vegetarians who consume less than 0.1 ìmol/ $\mathrm{kg} /$ day, representing about $1 \mathrm{mg} /$ day for a $70-\mathrm{kg}$ adult, and an average person with a diet providing a daily intake of $2-12 \mu \mathrm{mol} / \mathrm{kg} /$ day, or 23-135 mg per day for an average adult ${ }^{44}$; however, the extent of absorption in the subjects fed with a low-carnitine diet may be $75 \%$, on average ${ }^{45}$ while in subjects on a high-carnitine diet, $37 \%$ of the dose can be accounted for as excreted metabolites, meaning that the extent of absorption might be about $63 \%$. Then the efficiency of absorption tends to diminish as the carnitine content of the diet increases ${ }^{45,46}$, reflecting the involvement of specific transporters that can be saturated even with normal dietary intake. On the other hand, the bioavailability of supplemental or medicinal oral doses of L-carnitine tends to be even lower, at 5\%-18\%. Loss of endogenous L-carnitine from the body primarily occurs via renal excretion in the form of L-carnitine, acetyl-L-carnitine and longer chain esters. In a 24-hour period, a healthy human consuming a normal diet excretes between 100 and $300 \mu \mathrm{mol}$ of total carnitine, although the overall rate of excretion varies according to dietary intake ${ }^{47}$. Because L-carnitine is not bound to plasma protein ${ }^{48}$, it is extensively filtered at the glomerulus. However, tubular re-absorption ensures that only a small fraction of the filtered load is excreted in urine. In healthy individuals, the fractional tubular re-absorption of Lcarnitine (and acyl-L-carnitine derivatives) exceeds $90 \%$ and is probably greater than $98 \%$ under normal homeostatic conditions ${ }^{49,50}$. If the tubular re-absorption of L-carnitine is impaired due to disease or the administration of compounds that inhibit the renal tubular transport of the compound, the result is an increased urinary loss, and a systemic deficiency may develop ${ }^{51,52}$. In renal Fanconi syndrome, a significant reduction in the tubular re-absorption of L-carnitine results in a secondary deficiency of L-carnitine in plasma and muscle ${ }^{53}$. In some specific cases like training and exercise, the information obtained is somewhat controversial, given that some authors have found evidence for a beneficial effect of L-carnitine 
supplementation during training, competition, and recovery from strenuous exercise and during regenerative athletics ${ }^{54}$, in contrast to others ${ }^{55,56}$; however, experimental findings support the statement that Lcarnitine supplementation does not promote weight $\operatorname{loss}^{57-60}$.

\section{CONCLUSIONS}

After detailed analysis of the biochemical means in which carnitine is implicated, it can be concluded that carnitine supplementation does not promote weight loss and that carnitine supplementation is only recommended in secondary carnitine deficiency and some inherited inborn errors based on some important positions:

- Carnitine is a very important osmolite needed to import long-chain fatty acids into mitochondria for $\beta$-oxidation. However, the homeostasis of carnitine is kept through very efficient mechanisms such as the ability of the human body to synthesize sufficient amounts of carnitine even under adverse dietetic management and a very efficient tubular reabsorption of carnitine under normal conditions.

- The carnitine cycle depends basically on a good production and an adequate function of the enzymes carnitine palmiotyl transferase I, carnitine acylcarnitine translocase, and carnitine palmitoyl transferase II, whose production is not stimulated by carnitine.

- Carnitine does not promote fat degradation and mobilization from adipose tissue to others tissues for energy production, as can be achieved by some hormones like glucagon.

- Negative changes in the efficiency of absorption of carnitine are present when the content of carnitine in the diet increases.

\section{REFERENCES}

1. Winter SC. Treatment of carnitine deficiency. J Inherit Metab Dis. 2003; 26: 171-80.

2. Matera M, Bellinghieri G, Costantino G, Santoro D, Calvani M, Savica V. History of L-carnitine: implications for renal disease. J Ren Nutr. 2003; 13: 2-14.

3. Rebouche CJ. Kinetics, pharmacokinetics, and regulation of L-carnitine and acetyl-L-carnitine metabolism. Ann N Y Acad Sci. 2004; 1033: 30-41.
4. Rebouche C. Carnitine. In: Shils M, Shike M, Ross A, et al. Modern nutrition in health and disease. Philadelphia: Lippincott, Williams and Wilkins; 2006. p. 537-44.

5. Wanders RJA, Vreken P, Ferdinandusse S, Jansen GA, Waterham HR, van Roermund CWT, et al. Peroxisomal fatty acid $\alpha$ - and $\beta$-oxidation in humans: enzymology, peroxisomal metabolite transporters and peroxisomal diseases. Biochem Soc Trans. 2001; 29: 250-67.

6. Peluso G, Barbarisi A, Savica V, Reda E, Nicolai R, Benatti P, et al. Carnitine: an osmolyte that plays a metabolic role. $J$ Cell Biochem. 2000; 80: 1-10.

7. Pessayre D. Role of mitochondria in non-alcoholic fatty liver disease. J Gastroenterol Hepatol. 2007; 22( Suppl 1): S20-7.

8. Eaton S, Fukumoto K, Stefanutti G, Spitz L, Zammit VA, Pierro A. Myocardial carnitine palmitoyltransferase I as a target for oxidative modification in inflammation and sepsis. Biochem Soc Trans. 2003; 31: 1133-6.

9. Crill CM, Helms RA. The use of carnitine in pediatric nutrition. Nutr Clin Pract. 2007; 22: 204-13.

10. Poirier Y, Antonenkov VD, Glumoff T, Hiltunen JK. Peroxisomal beta-oxidation-a metabolic pathway with multiple functions. Biochim Biophys Acta. 2006; 1763: 1413-26.

11. Wanders RJ, Ferdinandusse S, Brites P, Kemp S. Peroxisomes, lipid metabolism and lipotoxicity. Biochim Biophys Acta. 2010; 1801: 272-80.

12. Dutta-Roy AK. Cellular uptake of long-chain fatty acids: role of membrane-associated fatty-acid-binding/transport proteins. Cell Mol Life Sci. 2000; 57:1360-72.

13. McGarry JD. Travels with carnitine palmitoyltransferase I: from liver to germ cell with stops in between. Biochem Soc Trans. 2001; 29: 241-5.

14. Ronnett GV, Kleman AM, Kim EK, Landree LE, Tu Y. Fatty acid metabolism, the central nervous system, and feeding. Obesity. 2006; 14 (Suppl 5): S201-7.

15. Baker A, Graham IA, Holdsworth M, Smith SM, Theodoulou FL. Chewing the fat: beta-oxidation in signaling and development. Trends Plant Sci. 2006; 11: 124-32.

16. Demizieux L. Control and regulation of mitochondrial oxidation of long-chained fatty acids. J Soc Biol. 2005; 199: 143-55.

17. Bennet MJ, Rinaldo P, Strauss AW. Inborn errors of mitochondrial fatty acid oxidation. Clin Rev Clin Lab Sci. 2000; 37: 1-44.

18. Harris WS, Bulchandani D. Why do omega-3 fatty acids lower serum triglycerides? Curr Opin Lipidol. 2006; 17: 387-93.

19. Czeczot H, Scibior D. Role of L-carnitine in metabolism, nutrition and therapy. Postepy Hig Med Dosw. 2005; 59: 9-19.

20. Longo N, Amat di San Filippo C, Pasquali M. Disorders of carnitine transport and the carnitine cycle. Am J Med Genet $C$ Semin Med Genet. 2006; 142C: 77-85.

21. Labadaridis J, Mavridou I, Sarafidou G, Alexiou N, Costalos C, Michelakakis H. Carnitine supplementation and ketogenesis by small-for-date neonates on medium-and long-chain fatty acid formulae. Biol Neonate. 2000; 77: 25-8.

22. Infante JP, Huszagh VA. Secondary carnitine deficiency and impaired docosahexaenoic (22:6n-3) acid synthesis: a common denominator in the pathophysiology of diseases of oxidative 
phosphorilation and $\beta$-oxidation. FEBS letters. 2000; 468: 1 5.

23. Laviano A, Meguid MM, Guijarro A, Muscaritoli M, Cascino A, Preziosa I, et al. Antimyopathic effects of carnitine and nicotine. Curr Opin Clin Nutr Metab Care. 2006; 9: 442-8.

24. Iyer RN, Khan AA, Gupta A, Vajifdar BU, Lokhandwala YY. L-carnitine moderately improves the exercise tolerance in chronic stable angina. J Assoc Physicians India. 2000; 48: 1050-2.

25. Lango R, Smolenski RT, Narkiewicz M, Suchorzewska J, Lysiak-Szydlowska W. Influence of L-carnitine and its derivatives on myocardial metabolism and function in ischemic heart disease and during cardiopulmonary bypass. Cardiovasc Res. 2001; 51: 21-9.

26. Rizos I. Three-year survival of patients with heart failure caused by dilated cardiomyopathy and L-carnitine administration. Am Heart J. 2000; 139: S120-3.

27. Gürlek A, Tutar E, Akçil E, Dinçer I, Erol C, Kocatürk PA, Oral D. The effects of L-carnitine treatment on left ventricular function and erythrocyte superoxide dismutase activity in patients with ischemic cardiomyopathy. Eur J Heart Fail. 2000; 2: 189-93.

28. Gaby AR. Nutritional treatments for acute myocardial infarction. Altern Med Rev. 2010; 15: 113-23.

29. Sirtori CR, Calabresi L, Ferrara S, Pazzucconi F, Bondioli A, Baldassarre D, Birreci A, Koverech A. L-carnitine reduces plasma lipoprotein(a) levels in patients with hyper Lp(a). Nutr Metab Cardiovasc Dis. 2000; 10: 247-51.

30. Derosa G, Cicero AF, Gaddi A, Mugellini A, Ciccarelli L, Fogari R. The effect of L-carnitine on plasma lipoprotein(a) levels in hypercholesterolemic patients with type 2 diabetes mellitus. Clin Ther. 2003; 25: 1429-39.

31. Cakir N, Yetkin I, Karakoc A, Karakan T, Ayvaz G, Arslan M. L-carnitine in the treatment of painful diabetic neuropathy and its effect on plasma beta-endorphin levels. Curr Ther Res Clin Exp. 2000; 61: 871-6.

32. Kuratsune H. Chronic fatigue syndrome. Ryoikibetsu Shokogun Shirizu. 2000; 32: 531-4.

33. Karanth J, Jeevaratnam K. Effect of carnitine supplementation on mitochondrial enzymes in liver and skeletal muscle of rat after dietary lipid manipulation and physical activity. Indian J Exp Biol. 2010; 48: 503-10.

34. DaVanzo WJ, Ullian ME. L-carnitine administration reverses acute mental status changes in a chronic hemodialysis patient with hepatitis C infection. Clin Nephrol. 2002; 57: 402-05.

35. Moretti S, Famularo G, Marcellini S, Boschini A, Santini G, Trinchieri $\mathrm{V}$, et al. L-carnitine reduces lymphocyte apoptosis and oxidant stress in HIV-1-infected subjects treated with zidovudine and didanosine. Antioxid Redox Signal. 2002; 4: 391-403.

36. Benvenga S, Ruggeri RM, Russo A, Lapa D, Campenni A, Trimarchi F. Usefulness of L-carnitine, a naturally occurring peripheral antagonist of thyroid hormone action, in iatrogenic hyperthyroidism: a randomized, double-blind, placebocontrolled clinical trial. J Clin Endocrinol Metab. 2001; 86: 3579-94.

37. Lenzi A, Lombardo F, Sgrò P, Salacone P, Caponecchia L,
Dondero F, et al. Use of carnitine therapy in selected cases of male factor infertility: a double-blind crossover trial. Fertil Steril. 2003; 79: 292-300.

38. Veselá E, Racek J, Trefil L, Jankovy'ch V, Pojer M. Effect of L-carnitine supplementation in hemodialysis patients. Nephron. 2001; 88: 218-23.

39. Romagnoli GF, Naso A, Carraro G, Lidestri V. Beneficial effects of L-carnitine in dialysis patients with impaired left ventricular function: an observational study. Curr Med Res Opin. 2002; 18: 172-5.

40. Whitfield J, Smith T, Sollohub H, Sweetman L, Roe CR. Clinical effects of L-carnitine supplementation on apnea and growth in very low birth weight infants. Pediatrics. 2003; 111: 477-82.

41. Peña-Quintana L, Sanjurjo-Crespo P. Diagnostic approach and treatment of inherited mitochondrial fatty acid oxidation disorders. An Esp Pediatr. 2001; 55: 524-34.

42. Stanley CA. Carnitine deficiency disorders in children. Ann $N$ Y Acad Sci 2004; 1033: 42-51.

43. Vaz FM, Wanders RJA. Carnitine biosynthesis in mammals. Biochem J. 2002; 361: 417-29.

44 Krajcovicová-Kudlácková M, Simoncic R, Béderová A, Babinská K, Béder I. Correlation of carnitine levels to methionine and lysine intake. Physiol Res. 2000; 49: 399-402.

45. Pace S, Longo A, Toon S, Rolan P, Evans AM. Pharmacokinetics of propionyl-L-carnitine in humans: evidence for saturable tubular reabsorption. Br J Clin Pharmacol. 2000; 50: 441-8.

46. Fokkema MR, van Rieke HM, Bauermann OJ, Smit EN, Muskiet FA. Short-term carnitine supplementation does not augment LCPomega3 status of vegans and lacto-ovovegetarians. J Am Coll Nutr. 2005; 24: 58-64.

47. Spiekerkoetter U, Bastin J, Gillingham M, Morris A, Wijburg F, Wilcken B. Current issues regarding treatment of mitochondrial fatty acid oxidation disorders. J Inherit Metab Dis. 2010; 33: 555-61.

48. Baek JE, Yang WS, Chang JW, Kim SB, Park SK, Park JS, Lee SK. Fatty acid-bearing albumin induces VCAM-1 expression through c-Src kinase-AP-1/NF-kB pathways: effect of Lcarnitine. Kidney Blood Press Res. 2010; 33: 72-84.

49. Chapela SP, Kriguer N, Fernández EH, Stella CA. Involvement of L-carnitine in cellular metabolism: beyond Acyl-CoA transport. Mini Rev Med Chem. 2009; 9: 1518-26.

50. Karanth J, Jeevaratnam K. Effect of carnitine supplementation on mitochondrial enzymes in liver and skeletal muscle of rat after dietary lipid manipulation and physical activity. Indian J Exp Biol. 2010; 48: 503-10.

51. Laforêt P, Vianey-Saban C. Disorders of muscle lipid metabolism: diagnostic and therapeutic challenges. Neuromuscul Disord. 2010; 20: 693-700.

52. Berardo A, DiMauro S, Hirano M. A diagnostic algorithm for metabolic myopathies. Curr Neurol Neurosci Rep. 2010; 10: 118-26.

53. Bökenkamp A, Ludwig M. Disorders of the renal proximal tubule. Nephron Physiol. 2011; 118: 1-6.

54. Karlic H, Lohninger A. Supplementation of L-carnitine in athletes: does it make sense? Nutrition. 2004; 20: 709-15. 
55. Jacobs PL, Goldstein ER. Long-term glycine propionyl-1carnitine supplemention and paradoxical effects on repeated anaerobic sprint performance. J Int Soc Sports Nutr. 2010; 7: 35 .

56. Kraemer WJ, Volek JS, Dunn-Lewis C. L-carnitine supplementation: influence upon physiological function. Curr Sports Med Rep. 2008; 7: 218-23.

57. Villani RG, Gannon J, Self M, Rich PA. L-Carnitine supplementation combined with aerobic training does not promote weight loss in moderately obese women. Int J Sport Nutr Exerc Metab. 2000; 10: 199-207.
58. Melton SA, Keenan MJ, Stanciu CE, Hegsted M, ZablahPimentel EM, O'Neil CE, et al. L-carnitine supplementation does not promote weight loss in ovariectomized rats despite endurance exercise. Int J Vitam Nutr Res. 2005; 75: 156-60.

59. Elmslie JL, Porter RJ, Joyce PR, Hunt PJ, Mann JI. Carnitine does not improve weight loss outcomes in valproate-treated bipolar patients consuming an energy-restricted, low-fat diet. Bipolar Disord. 2006; 8 (5 Pt 1): 503-7.

60. Saper RB, Eisenberg DM, Phillips RS. Common dietary supplements for weight loss. Am Fam Physician. 2004; 70: 1731-8. 